\title{
Heteroaggregation and sedimentation rates for nanomaterials in natural waters
}

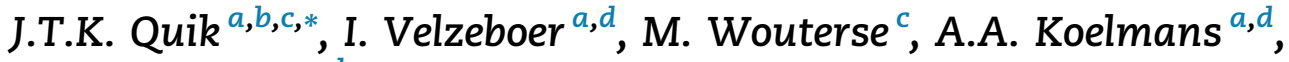 \\ D. van de Meent ${ }^{b}$
}

a Aquatic Ecology and Water Quality Management Group, Department of Environmental Sciences, Wageningen University, P.O. Box 47, 6700 AA Wageningen, The Netherlands

${ }^{\mathrm{b}}$ Radboud University Nijmegen, Institute for Wetland and Water Research, Department of Environmental Science, P.O. Box 9010, 6500 GL Nijmegen, The Netherlands

${ }^{\mathrm{c}}$ Laboratory for Ecological Risk Assessment, National Institute for Public Health and the Environment (RIVM), P.O. Box 1, 3720 BA Bilthoven, The Netherlands

${ }^{\mathrm{d}}$ IMARES - Institute for Marine Resources and Ecosystem Studies, Wageningen UR, Haringkade 1, 1976 CP IJmuiden, The Netherlands

\section{A R T I C L E I N F O}

Article history:

Received 17 July 2013

Received in revised form

16 September 2013

Accepted 17 September 2013

Available online $\mathrm{xxx}$

Keywords:

Heteroaggregation rate

Attachment efficiency

Sedimentation

Nanomaterial

Natural colloid

\begin{abstract}
A B S T R A C T
Exposure modeling of engineered nanomaterials requires input parameters such as sedimentation rates and heteroaggregation rates. Here, we estimate these rates using quiescent settling experiments under environmentally relevant conditions. We investigated 4 different nanomaterials $\left(\mathrm{C}_{60}, \mathrm{CeO}_{2}, \mathrm{SiO}_{2}-\mathrm{Ag}\right.$ and $\left.\mathrm{PVP}-\mathrm{Ag}\right)$ in 6 different water types ranging from a small stream to seawater. In the presence of natural colloids, sedimentation rates ranged from $0.0001 \mathrm{~m} \mathrm{~d}^{-1}$ for $\mathrm{SiO}_{2}-\mathrm{Ag}$ to $0.14 \mathrm{~m} \mathrm{~d}^{-1}$ for $\mathrm{C}_{60}$. The apparent rates of heteroaggregation between nanomaterials and natural colloids were estimated using a novel method that separates heteroaggregation from homoaggregation using a simplified Smoluchowski-based aggregation-settling equation applied to data from unfiltered and filtered waters. The heteroaggregation rates ranged between 0.007 and $0.6 \mathrm{~L} \mathrm{mg}^{-1} \mathrm{day}^{-1}$, with the highest values observed in seawater. We argue that such system specific parameters are key to the development of dedicated water quality models for ENMs.
\end{abstract}

(c) 2013 Elsevier Ltd. All rights reserved.

\section{Introduction}

The production and use of engineered nanomaterials (ENMs) are growing, which increases their emission to environmental compartments (Nowack and Bucheli, 2007). Consequently, understanding the safety, environmental and human health implications of nanotechnology-based products is of worldwide importance (Klaine et al., 2012; Wiesner et al., 2006).
Although the benefits of ENMs have shown to be manifold, the implication of large quantities of ENMs entering the environment has yet to be understood (Batley et al., 2013; Hendren et al., 2011). There is a growing need for risk assessment of different nanomaterials in order to support their safe production and use (Morris et al., 2011). The environmental risk assessment is based on the determination of adverse effects on organisms and on evaluation of the environmental

\footnotetext{
* Corresponding author. P.O. Box 47, 6700 AA Wageningen, The Netherlands. Tel.: +31 317 484150; fax: +31 317484411.

E-mail address: joris.quik@wur.nl (J.T.K. Quik).
} 
concentrations to which biota are exposed (EU, 2008; Quik et al., 2011). Recently, modeling approaches for estimating the environmental exposure concentration of nanomaterials have been suggested (Arvidsson et al., 2011; Gottschalk et al., 2010; Praetorius et al., 2012; Quik et al., 2011). These studies acknowledge the lack of input parameters valid for environmentally relevant conditions, such as sedimentation rates in natural waters (Gottschalk et al., 2010; Quik et al., 2011) and heteroaggregation rates for collisions between natural colloids (NCs) and ENMs (Arvidsson et al., 2011; Praetorius et al., 2012). Since there is no validated framework for calculation of these parameters for ENMs, they need to be estimated experimentally (Hotze et al., 2010; Lin et al., 2010; Petersen et al., 2011; Westerhoff and Nowack, 2013).

The aggregation rate constants for heteroaggregation $\left(k_{\text {het }}\right)$ can be split up in the product of collision frequency $(K)$ and the attachment efficiency $(\alpha)$, i.e. $k_{\text {het }}=K \times \alpha$ (Friedlander, 2000; Petosa et al., 2010). For homoaggregation, several studies use this approach to derive the attachment efficiency $\alpha_{\text {homo }}$ as an important parameter driving homoaggregation kinetics for a certain ENM under a range of test conditions, such as ionic strength or DOC concentration (Chen and Elimelech, 2008; Keller et al., 2010). Consequently, such attachment efficiencies are conditional and represent the average behavior of particles present. The uncertain and conditional nature of $K$ and $\alpha$ may be even bigger for heteroaggregation because natural colloids can be assumed to be much more heterogeneous and fundamentally indeterminate. Current methods to estimate attachment efficiencies $\alpha$ from observed aggregation rates rely on the collision frequency $\mathrm{K}$ being constant or known among a range of test conditions. However, due to the range of water and NC characteristics present in natural systems, the collision frequency $\mathrm{K}$ will not be constant. Furthermore, current theory of colloid behavior is not likely to be sufficient to estimate the collision frequency for natural systems. After all, this theory is based on ideal systems with spherical particles. In practice, fate models or water quality models for nanoparticles do not require separate attachment efficiencies $\alpha$, nor separate collision frequencies $K$. They require the aforementioned product $k_{\text {het }}=K \times \alpha$ (Arvidsson et al., 2011; Praetorius et al., 2012). The heteroaggregation rate constant $k_{\text {het }}$ is the primary parameter used in current exposure modeling approaches which take heteroaggregation into account (Praetorius et al., 2012). We argue that conditional values of $k_{\text {het }}$ are highly needed for the further development of fate models for ENMs.

In the present study we provide estimates of sedimentation rates and heteroaggregation rate constants, based on sedimentation data for 4 different ENMs in the presence and absence of NCs in 6 different natural water types. Heteroaggregation rates are usually measured by directly measuring the increase in particle size in time (Afrooz et al., 2013; Huynh et al., 2012). For natural waters, direct measurement of aggregation rates is problematic due to the limitations of measurement techniques for such complex systems. We therefore propose a novel method to estimate these heteroaggregation rates from sedimentation data. We used fullerene $\left(C_{60}\right)$ as a carbon based ENM, Cerium dioxide $\left(\mathrm{CeO}_{2}\right)$ ENM as a metal oxide and Silver (Ag) ENM with two different coatings, polyvinylpyrrolidone (PVP) and silicon dioxide $\left(\mathrm{SiO}_{2}\right)$. Quiescent settling was measured in water from six different water bodies ranging from a small pond and stream to lake and seawater. These water samples cover a range in water quality characteristics such as salinity, acidity and organic matter content. Earlier work showed that NCs governed the sedimentation of ENMs in river water (Rhine and Meuse) (Quik et al., 2012). Here, this mechanism is studied for a much wider range of water types, including brackish tidal water and marine water. Sedimentation rates and heteroaggregation rates for ENMs and NCs are reported. To our knowledge, this is the first study that reports these parameters on the interaction of ENMs with NCs in surface waters.

\section{Materials and methods}

\subsection{Engineered nanomaterials}

Polyvinylpyrrolidone coated silver (PVP-Ag) nanoparticles (hydrodynamic diameter $\left(d_{h}\right): 90.5 \mathrm{~nm}$ ) and $\mathrm{SiO}_{2}$ coated silver $\left(\mathrm{SiO}_{2}-\mathrm{Ag}\right)$ nanoparticles $\left(d_{h}: 124 \mathrm{~nm}\right)$ were purchased from nanoComposix (San Diego, CA). Ceriumdioxide $\left(\mathrm{CeO}_{2}\right)$ nanoparticles $\left(d_{h}: 175 \mathrm{~nm}\right)$ were kindly supplied by Umicore Ltd. (Brussels), as part of the EU NanoInteract project. $\mathrm{CeO}_{2}$ nanoparticles from the same batch have previously been used in several fate and effect studies (Quik et al., 2010, 2012; Van Hoecke et al., 2011; Van Hoecke et al., 2009). Fullerene $\left(C_{60}\right.$, $\left.d_{h}: 217 \mathrm{~nm}\right), 99 \mathrm{wt} \%$ purity was obtained as powder from Cheaptubes (Brattleboro, VT). A $\mathrm{C}_{60}$ nanoparticles stock suspension was prepared by dispersing $1 \mathrm{~g} \mathrm{~L}^{-1} \mathrm{C}_{60}$ in deionized water by shaking $(150 \mathrm{rpm})$ for 4 weeks in a glass bottle screened from sunlight. Other properties and electron microscopy images of the ENMs are provided as Supporting Information (Table A1, Figure A1, Figure A2).

Particle size distribution and particle number concentration were measured using nanoparticle tracking analysis (NTA). This was done using the NanoSight LM 20 (NanoSight Ltd., Salisbury, UK) using a previously described method (Quik et al., 2010) and NTA software version 2.2. It should be noted that the NTA method is not very sensitive to particles $<50 \mathrm{~nm}$ with a low refractive index and particles $>1500 \mathrm{~nm}$. This implies that the NTA based characteristics are operationally defined. Electrophoretic mobility was measured with a ZetaSizer instrument (nano series, Malvern Instruments Ltd., Worcestershire, UK). Throughout this paper, the term 'concentration' refers to mass concentration unless indicated otherwise.

\subsection{Water sampling}

Six different natural waters were sampled using polyethylene containers. Samples were taken from the North Sea (NZ, coastal sea), Rhine (RL, river), Brabantse Aa (AA, small stream), IJsselmeer (IJ, freshwater lake), Nieuwe Waterweg (MS, tidal water), and Karregata (KG, small acid pond), all located in the Netherlands. Details on sampling and exact locations are provided as Supporting Information (Table A2). Sedimentation experiments were started on the same day of sampling. To remove NCs, part of the water was filtered with $0.2 \mu \mathrm{m}$ membrane filters (Nuclepore filters, PALL), following earlier 
Table 1 - Characteristics of the natural waters: Karregat (KG), Brabantse Aa (AA), Rhine (RL), IJsselmeer (IJ), Maassluis (MS) and North Sea (NZ).

\begin{tabular}{|c|c|c|c|c|c|c|}
\hline & KG & AA & RL & IJ & MS & NZ \\
\hline $\mathrm{pH}(-)$ & 4.61 & 6.69 & 7.95 & 8.33 & 7.89 & 7.78 \\
\hline EC (uS/cm) & 67.1 & 434 & 584.3 & 763 & 7200 & 47,000 \\
\hline $\mathrm{O}_{2}(\mathrm{mg} / \mathrm{L})$ & 8.94 & 7.55 & 9.27 & 10.83 & 7.92 & 8.38 \\
\hline $\mathrm{Cl}(\mathrm{mg} / \mathrm{L})$ & 9.9 & 57.5 & 126 & 146 & 3970 & 28,600 \\
\hline $\mathrm{NO}_{3}+\mathrm{NO}_{2}(\mathrm{mg} \mathrm{N} / \mathrm{L})$ & 0.2 & 6.25 & 2.75 & 1.88 & 2.44 & 0.26 \\
\hline $\mathrm{PO}_{4}(\mu \mathrm{g} \mathrm{P} / \mathrm{L})$ & 48.2 & 102.4 & 36.1 & 28.4 & 103.4 & n.a. ${ }^{a}$ \\
\hline $\mathrm{NH}_{3}(\mathrm{mg} \mathrm{N} / \mathrm{L})$ & 0.18 & 0.59 & 0.03 & 0.1 & 0.07 & 0.02 \\
\hline Total P (mg P/L) & 0.01 & 0.16 & 0.04 & 0.02 & 0.12 & 0.12 \\
\hline Total N (mg N/L) & 0.34 & 5.14 & 1.68 & 1.45 & 1.72 & 0.06 \\
\hline $\mathrm{Ca}(\mathrm{mg} / \mathrm{L})$ & 3.7 & 36 & 55.7 & 55.4 & 104 & 401 \\
\hline $\mathrm{K}(\mathrm{mg} / \mathrm{L})$ & 1.2 & 13.7 & 4.4 & 7.4 & 50 & 371 \\
\hline $\mathrm{Mg}(\mathrm{mg} / \mathrm{L})$ & 1.94 & 7.7 & 10.6 & 12.3 & 160 & 1233 \\
\hline $\mathrm{Na}(\mathrm{mg} / \mathrm{L})$ & 13.9 & 22.7 & 46.2 & 59.1 & 1370 & 10,630 \\
\hline DIC (mg C/L) & 0.69 & 23.02 & 24.62 & 30.23 & 31.22 & 40.91 \\
\hline DOC (mg C/L) & 5.45 & 25.98 & 2.45 & 5.62 & 2.85 & 0.17 \\
\hline $\mathrm{NCs}^{\mathrm{b}}(\mathrm{mg} / \mathrm{L})$ & 1.9 & 7.1 & 10.3 & 2.9 & 11.9 & 2.6 \\
\hline $\operatorname{NCs}^{c}\left(10^{8} / \mathrm{L}\right)$ & 0.65 & 3.39 & 0.72 & 0.51 & 0.54 & 0.10 \\
\hline Radius $\mathrm{NC}^{\mathrm{C}}(\mathrm{nm})$ & $351 \pm 46$ & $286 \pm 31$ & $291 \pm 47$ & $225 \pm 30$ & $319 \pm 49$ & $348 \pm 163$ \\
\hline \multicolumn{7}{|c|}{$\begin{array}{l}\text { a No data available. } \\
\text { b Measured using dry weight after filtration. } \\
\text { c Operationally defined measurements using nanoparticle tracking analysis, which is limited in sensitivity at the lower ( }<50 \text { nm) and higher } \\
\text { (>1500 nm) particle size ranges. }\end{array}$} \\
\hline
\end{tabular}

studies (Hyung et al., 2007; Quik et al., 2012). This filtration technique reduces NC concentrations to negligible levels (Figure A4). After measuring $\mathrm{pH}$, EC and $\mathrm{O}_{2}$ content, samples were stored at $-20{ }^{\circ} \mathrm{C}$ before further elemental analysis. Dissolved organic carbon (DOC) was measured by adding $\mathrm{HNO}_{3}$ and purging with $\mathrm{O}_{2}$ using HiperTOC (Thermo, Delft, NL). The six water types mainly differed in ionic strength, $\mathrm{pH}$ and DOC content (Table 1). Electric conductivity as an indicator of ionic strength ranged between $47,000 \mu \mathrm{S} \mathrm{m}^{-1}$ for seawater (NZ), followed by brackish water (MS) and the different fresh water types (IJ, RL, AA, KG) of which the lowest value was $67.1 \mu \mathrm{S} \mathrm{cm}^{-1}$ (Table 1). DOC concentration was highest at AA (26 $\left.\mathrm{mg} \mathrm{C} \mathrm{L}^{-1}\right)$ and lowest at NZ $\left(0.17 \mathrm{mg} \mathrm{C} \mathrm{L}^{-1}\right)$. The $\mathrm{pH}$ was lowest at $\mathrm{KG}(\mathrm{pH}=4.6)$ whereas the $\mathrm{pH}$ of the five other water types ranged from 6.7 to 8.3. MS and RL water had the highest concentration of natural particulate matter $\left(>10 \mathrm{mg} \mathrm{L}^{-1}\right)$, whereas NZ, KG and IJ water had the lowest concentration of natural particulate matter $\left(<3 \mathrm{mg} \mathrm{L}{ }^{-1}\right)$. An overview of all chemical characteristics of the water samples is provided in Table 1.

\subsection{Sedimentation experiments}

Sedimentation of $\mathrm{CeO}_{2}, \mathrm{PVP}-\mathrm{Ag}, \mathrm{SiO}_{2}-\mathrm{Ag}$ and $\mathrm{C}_{60}$ nanoparticles was studied during 15 days with a method adapted from earlier work (Quik et al., 2010, 2012). Our experiments used a considerably longer sedimentation time than many other studies, in order to increase realism and accuracy in medium to long timescales. Three different doses of ENMs were added to each of the six water types in order to obtain dispersions of $0.5,2.5$ and, $10 \mathrm{mg} \mathrm{L}^{-1}$ for the metal ENMs, and 5, 25 and, $100 \mathrm{mg} \mathrm{L}^{-1}$ for the $\mathrm{C}_{60}$ nanoparticles. For $\mathrm{C}_{60}$ nanoparticles a higher dose was used because of the higher detection limit of the $\mathrm{UV}_{\text {vis }}$ method. After $0,1,2,6,10$ and 15 days, samples were taken for characterization and analysis of ENM concentrations. Samples of $5 \mathrm{~mL}$ were carefully taken by pipette at $3 \mathrm{~cm}$ below the water surface. Concentrations of $\mathrm{Ce}$ and Ag were taken as a proxy for ENM mass, and were measured by high-resolution inductively coupled plasmamass spectroscopy (Element 2 HR-ICP-MS, Thermo, Bremen, Germany). Before analysis, $4 \mathrm{~mL}$ of the supernatant sample was weighed into 50-mL tubes for digestion with $7 \mathrm{~mL} 14.4 \mathrm{M}$ nitric acid and $1 \mathrm{~mL} 9.8 \mathrm{M}$ hydrogen peroxide at $103^{\circ} \mathrm{C}$ for $2 \mathrm{~h}$ (Ce measurements). For Ag measurement, $7 \mathrm{~mL} \mathrm{37 \%} \mathrm{w/w} \mathrm{HCl}$ was added. Concentration of $\mathrm{C}_{60}$ were measured by extraction using $0.01 \mathrm{M} \mathrm{Mg}\left(\mathrm{ClO}_{4}\right)_{2}$ from water to $2.5 \mathrm{~mL}$ toluene after shaking for $30 \mathrm{~min}$. Subsequently, the absorbance in $1 \mathrm{~mL}$ toluene $\mathrm{C}_{60}$ extracts was measured at $335 \mathrm{~nm}$ in triplicate.

\subsection{Dissolution}

At the start and after 15 days the dissolved fraction of metals in the water phase was measured by centrifugal filtering for $15 \mathrm{~min}$ at 14,000 rpm. Particulate and dissolved fractions were separated by means of $3 \mathrm{kDa}$ filters (PALL). To prevent reported effects of $\mathrm{Ag}^{+}$loss from adsorption to the filter, filters were pre-treated with $\mathrm{Cu}$ solution (Cornelis et al., 2010). $1 \mathrm{~mL}$ samples were collected from two filters and Ag and Ce concentration was measured using HR-ICP-MS (see above). The chemical speciation program CHEAQS (Verweij, 2011) was used to calculate chemical species present at the measured water composition.

\subsection{Estimation of sedimentation rates}

Sedimentation data were interpreted using a semi-empirical model adapted from Newman et al. (1990) and Quik et al. 
Table 2 - Sedimentation rates $\left(V_{s}\right)$, non-settling concentration $\left(C_{n s}\right)$ and apparent heteroaggregation rates ( $\left.k_{h e t . c r i t t}\right)$ for $C_{60}$, $\mathrm{CeO}_{2}, \mathrm{SiO}_{2}-\mathrm{Ag}$ and PVP-Ag ENMs in natural waters in presence of natural colloids.

\begin{tabular}{|c|c|c|c|c|c|c|c|}
\hline & & $\mathrm{KG}$ & AA & RL & IJ & MS & $\mathrm{NZ}$ \\
\hline \multirow[t]{3}{*}{$\mathrm{C}_{60}$} & $V_{s}\left(\mathrm{~m} \mathrm{~d}^{-1}\right)$ & 0.102 & 0.109 & 0.136 & $8.81 \cdot 10^{-2}$ & 0.139 & $4.11 \cdot 10^{-2}$ \\
\hline & $\mathrm{C}_{\mathrm{ns}}\left(\mathrm{mg} \mathrm{L}^{-1}\right)$ & $4.06 \cdot 10^{-2}$ & $7.17 \cdot 10^{-2}$ & $6.09 \cdot 10^{-2}$ & $1.78 \cdot 10^{-2}$ & $1.81 \cdot 10^{-2}$ & $2.29 \cdot 10^{-2}$ \\
\hline & $k_{\text {het.crit }}\left(\mathrm{L} \mathrm{mg}^{-1} \mathrm{day}^{-1}\right)^{\mathrm{a}}$ & n.a. ${ }^{b}$ & $6.82 \cdot 10^{-3}$ & n.a. ${ }^{b}$ & n.a. ${ }^{b}$ & $1.49 \cdot 10^{-1}$ & $6.00 \cdot 10^{-1}$ \\
\hline \multirow[t]{3}{*}{$\mathrm{CeO}_{2}$} & $V_{s}\left(\mathrm{~m} \mathrm{~d}^{-1}\right)$ & $6.10 \cdot 10^{-4}$ & $1.39 \cdot 10^{-3}$ & $3.09 \cdot 10^{-2}$ & $5.44 \cdot 10^{-3}$ & $7.83 \cdot 10^{-3}$ & $6.94 \cdot 10^{-3}$ \\
\hline & $C_{\mathrm{ns}}\left(\mathrm{mg} \mathrm{L}^{-1}\right)$ & 0.270 & 0.309 & $2.46 \cdot 10^{-2}$ & $9.60 \cdot 10^{-2}$ & $1.68 \cdot 10^{-2}$ & $9.37 \cdot 10^{-3}$ \\
\hline & $k_{\text {het.crit }}\left(\mathrm{L} \mathrm{mg}^{-1} \text { day }^{-1}\right)^{\mathrm{a}}$ & $2.63 \cdot 10^{-2}$ & n.a. & $1.45 \cdot 10^{-1}$ & $5.12 \cdot 10^{-2}$ & $1.04 \cdot 10^{-1}$ & $1.14 \cdot 10^{-1}$ \\
\hline \multirow[t]{3}{*}{$\mathrm{SiO}_{2}-\mathrm{Ag}$} & $V_{s}\left(\mathrm{~m} \mathrm{~d}^{-1}\right)$ & $1.01 \cdot 10^{-4}$ & $1.34 \cdot 10^{-3}$ & $5.97 \cdot 10^{-3}$ & $2.42 \cdot 10^{-3}$ & $1.00 \cdot 10^{-2}$ & $5.33 \cdot 10^{-3}$ \\
\hline & $C_{\mathrm{ns}}\left(\mathrm{mg} \mathrm{L}^{-1}\right)$ & 0.285 & 0.179 & $5.16 \cdot 10^{-2}$ & 0.152 & $7.94 \cdot 10^{-2}$ & 0.164 \\
\hline & $k_{\text {het.crit }}\left(\mathrm{L} \mathrm{mg}^{-1} \mathrm{day}^{-1}\right)^{\mathrm{a}}$ & n.a. ${ }^{b}$ & $8.74 \cdot 10^{-3}$ & $1.34 \cdot 10^{-2}$ & $2.16 \cdot 10^{-2}$ & $1.54 \cdot 10^{-2}$ & $2.40 \cdot 10^{-2}$ \\
\hline \multirow[t]{3}{*}{ PVP-Ag } & $\mathrm{V}_{\mathrm{s}}\left(\mathrm{m} \mathrm{d}^{-1}\right)$ & $4.12 \cdot 10^{-3}$ & $3.06 \cdot 10^{-3}$ & $9.98 \cdot 10^{-3}$ & $8.22 \cdot 10^{-4}$ & n.a. & $1.61 \cdot 10^{-3}$ \\
\hline & $\mathrm{C}_{\mathrm{ns}}\left(\mathrm{mg} \mathrm{L}^{-1}\right)$ & 0.141 & 0.316 & $4.57 \cdot 10^{-2}$ & 0.116 & $4.06 \cdot 10^{-2}$ & 0.218 \\
\hline & $k_{\text {het.crit }}\left(\mathrm{L} \mathrm{mg}^{-1} \text { day }^{-1}\right)^{\mathrm{a}}$ & $6.96 \cdot 10^{-2}$ & n.a. ${ }^{b}$ & $2.54 \cdot 10^{-2}$ & $2.47 \cdot 10^{-2}$ & $5.01 \cdot 10^{-2}$ & $6.98 \cdot 10^{-2}$ \\
\hline $\begin{array}{l}\text { n.a.: no } \\
\text { a Start } \\
\text { b Not de }\end{array}$ & because of insufficie & entatio & $\begin{array}{l}\text { etero, crit. } \\
\text { heteroag }\end{array}$ & & & & \\
\hline
\end{tabular}

(2012), which describes the concentrations of ENMs in the supernatant $\left(C_{t}\left[\mathrm{~g} \mathrm{~L}^{-1}\right]\right)$ as a function of time:

$C_{t}=\left(C_{0}-C_{n s}\right) e^{-\left(\frac{V_{s}}{h}+k_{\text {dis }}\right) t}+C_{n s}$

The non-settling concentration $\left(C_{n s}\left[\mathrm{~g} \mathrm{~L}^{-1}\right]\right)$ represents the ENM concentration after infinite time based on data measured at 15 days. $V_{s}\left[\mathrm{~m} \mathrm{~d}^{-1}\right]$ is the apparent sedimentation rate, $h[\mathrm{~m}]$ is the sedimentation length, $k_{\text {dis }}\left[\mathrm{d}^{-1}\right]$ is the dissolution rate constant and $t$ is time [d]. This model was fitted to the data using the nonlinear least squares method in package stats in $\mathrm{R}$ (R Development Core Team, 2012). Due to the design of the sedimentation experiment, dissolution ( $k_{\text {dis }}$ in Eq. (1)) could not be inferred from the elemental concentration measurement in the supernatants of the settling experiments (section 2.5). After all, Ce, $\mathrm{Ag}$ or $\mathrm{C}_{60}$ in the supernatant were measured as total concentration, thus any decrease in concentration in time has to relate to sedimentation $\left(V_{s}\right)$ and not to dissolution $\left(k_{\text {dis }}\right)$. Instead, dissolution was studied by analyzing the Ag and Ce ion concentrations in ultra-filtered water.

In order to compare the obtained sedimentation rates (Table 2, $\mathrm{V}_{\mathrm{S}}$ ) to literature data, we converted previously reported sedimentation rate constants $\left[\mathrm{d}^{-1}\right]$ (Chinnapongse et al., 2011; Keller et al., 2010; Kennedy et al., 2008) to true sedimentation rates $\left[\mathrm{m} \mathrm{d}^{-1}\right]$ using a sedimentation length measured from the water surface to the measurement depth (calculations provided as Supporting Information).

\subsection{Estimation of heteroaggregation rates}

The basis for the calculation of the heteroaggregation rate is the combined Von Smoluchowski-Stokes equation (Friedlander, 2000):

$$
\begin{aligned}
\frac{\mathrm{d} N_{j}}{\mathrm{dt}}= & \frac{1}{2} \sum_{i=1}^{i=j-1} \alpha_{i, j-i} K_{i, j-i} N_{i} N_{j-i}-N_{j} \sum_{i=1}^{i=\infty} \alpha_{i, j} K_{i, j} N_{i}-\alpha_{\mathrm{NC}, j} K_{N C, j} N_{N C} N_{j} \\
& -\frac{v_{s, j}}{d_{s}} N_{j}
\end{aligned}
$$

in which $\alpha_{i, j}$ is the attachment efficiency between ENM aggregates $i$ and $j, \alpha_{N C, j}$ the attachment efficiency between ENM and NCs, $j$ the number of primary NPs in ENM aggregate $j, K_{i, j}$ the collision frequency between ENM aggregates $i$ and $j\left[\mathrm{~m}^{3} \mathrm{~s}^{-}\right.$ ${ }^{1}$ ], $K_{\mathrm{NC}, j}$ the collision frequency between ENM particle aggregates $j$ and $\mathrm{NCs}\left[\mathrm{m}^{3} \mathrm{~s}^{-1}\right], N_{j}$ is the number concentration of the ENM aggregate $j\left[\mathrm{~m}^{-3}\right], N_{\mathrm{NC}}$ is concentration of $\mathrm{NCs}\left[\mathrm{m}^{-3}\right], v_{\mathrm{s}, \mathrm{j}}$ is the sedimentation rate of ENM aggregate $j\left[\mathrm{~m} \mathrm{~s}^{-1}\right]$ and $d_{s}$ is the sedimentation length [m]. In Eq. (2), the first two terms account for growth to and loss from ENM size class $j$ due to homoaggregation, the third term accounts for heteroaggregation, and the last term for sedimentation of ENM aggregates. The concentration of natural colloids $C_{\mathrm{NC}}$ is assumed to decrease due to Stokes settling (Boyd, 1995; Filella, 2007);

$\frac{d N_{\mathrm{NC}}}{\mathrm{dt}}=-\frac{v_{s, \mathrm{NC}}}{d_{\mathrm{s}}} \mathrm{N}_{\mathrm{NC}}$

Eq. (2) is simplified based on a few informed assumptions, which subsequently are validated against extensive simulations obtained using the full deterministic Eq. (2) (simulation results provided as Supporting Information). Following Farley and Morel (1986), it is assumed that aggregation is the rate limiting process for the observed removal of ENMs from the water phase. This follows the logic that aggregates first need to be large enough for sedimentation to occur. This means that the aggregation terms in Eq. (2) are considered to be rate determining and that the last term in Eq. (2) can be omitted. Second, it is assumed that the summations in Eq. (2) can be replaced by single terms accounting for the apparent critical collision behavior for sedimentation. This is motivated as follows. The summation in Eq. (2) accounts for numerous collisions that will not (yet) lead to homo- or heteroaggregates large enough to settle. However, a certain fraction of all possible collisions will at some point reach a critical limit after which rapid settling occurs. The measured removal in the sedimentation experiments relate to this apparent removal of settleable ENMs only $\left(\mathrm{ENM}_{\mathrm{crit}}\right)$. Because size distributions of these settling ENP aggregates may not be monodisperse, the single terms are governed by apparent 

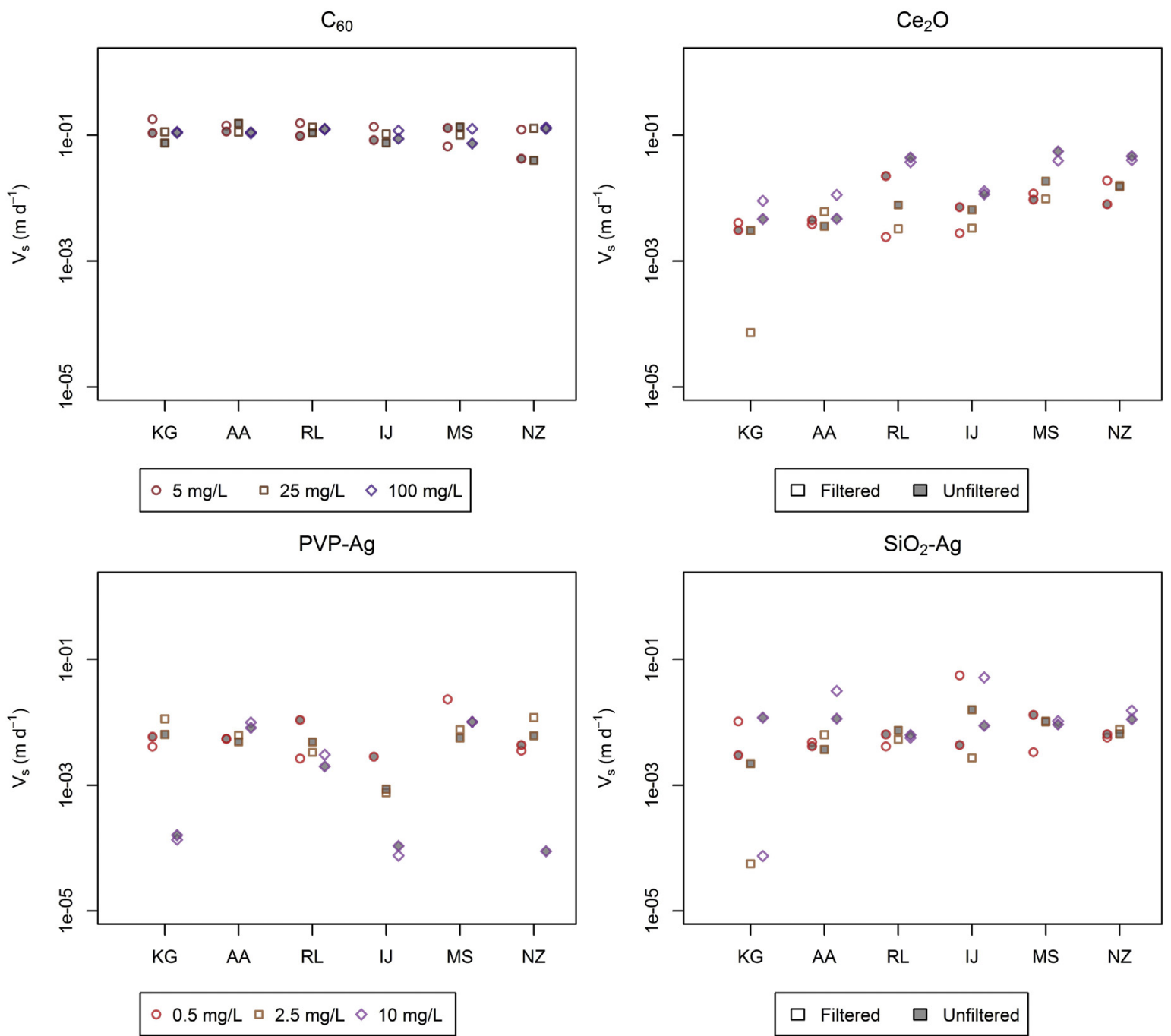

Fig. 1 - Sedimentation rates $\left(\mathrm{V}_{s}\right)$ for $\mathrm{C}_{60}, \mathrm{CeO}_{2}, \mathrm{PVP}-\mathrm{Ag}$ and $\mathrm{SiO}_{2}-\mathrm{Ag}$ nanoparticles in 6 different water types with (unfiltered) and without (filtered) natural colloids present, for 3 different initial ENM concentrations $\left(0.5,2.5\right.$ and $10 \mathrm{mg} \mathrm{L}^{-1}$ for metal ENMs and 5, 25, $100 \mathrm{mg} \mathrm{L}^{-1}$ for $\mathrm{C}_{60}$ ). Water types: Karregat (KG), Brabantse Aa (AA), Rhine (RL), IJsselmeer (IJ), Maassluis (MS) and North Sea (NZ).

parameters reflecting average properties of the particles at the onset of settling. Third, it is assumed that the ENM concentration change in the overlying water is determined by aggregation to settling particles only i.e. is not affected by progressive aggregation to larger particles. Progressive aggregation cannot affect $\mathrm{ENM}_{\text {crit }}$ concentrations beyond the critical size for sedimentation because they would have settled out already. This implies that the first two terms for aggregation in Eq. (2) can be combined. Consequently, Eq. (2) can be simplified to describe removal from the water column:

$\frac{\mathrm{dC}_{\mathrm{ENM}, \mathrm{crit}}}{\mathrm{dt}}=-k_{\text {hom,crit }} C_{\mathrm{ENM}, \text { crit }}^{q}-k_{\text {het,crit }} C_{\mathrm{NC}} C_{\mathrm{ENM}, \text { crit }}$

in which $C_{\mathrm{ENM}}$, crit is the concentration of settleable ENMs [ $\mathrm{g} \mathrm{L}^{-}$ ${ }^{1}$ ], $k_{\text {hom, crit }}$ is the apparent aggregation rate for the formation of settleable ENM homoaggregates [ $\left(\mathrm{L} \mathrm{g}^{-1}\right)^{1-\mathrm{q}} \mathrm{s}^{-1}$ ], and $k_{\text {het, crit }}$ is the apparent aggregation rate for the formation of settleable ENM heteroaggregates $\left[\mathrm{L} \mathrm{g}^{-1} \mathrm{~s}^{-1}\right.$ ]. The exponent $q$ defines the kinetics for homoaggregation and was obtained by fitting the analytical solution of Eq. (4) against simulations based on the full Von Smoluchowski-Stokes equation (Eq. (2)), yielding a value of $q \approx 1$ (details provided as Supporting Information). In summary, Eq. (4) describes how the concentration of the (operationally defined) settling ENM fraction changes over time, as a function of the processes that drive the production of aggregates. Aggregates that do not settle substantially in the time interval over which settling is monitored (15 days in the present experiments) are also formed. Primary particles may also be stabilized and not settle at all. The latter two categories of processes lead to an operationally defined nonsettling fraction $\left(C_{n s}\right.$ in Eq. (1)). Eq. (4) can be solved with $q=1$ and with Eq. (3) for the time dependence of $C_{\mathrm{NC}}$ to yield the analytical solution:

$C_{\text {ENM,crit }}(t)=C_{0, E N M, \text { crit }} e^{-A t+B\left(e^{-D t}-1\right)}$

where $A=k_{\text {hom.crit }}, B=k_{\text {het.crit }} C_{0, N C} d_{s} / v_{s, N C}$ and $D=v_{s, N C} / d_{s}$. The rate for heteroaggregation to settleable particles, $k_{\text {het.crit }}$, can be estimated by fitting Eq. (5) to the sedimentation data from 

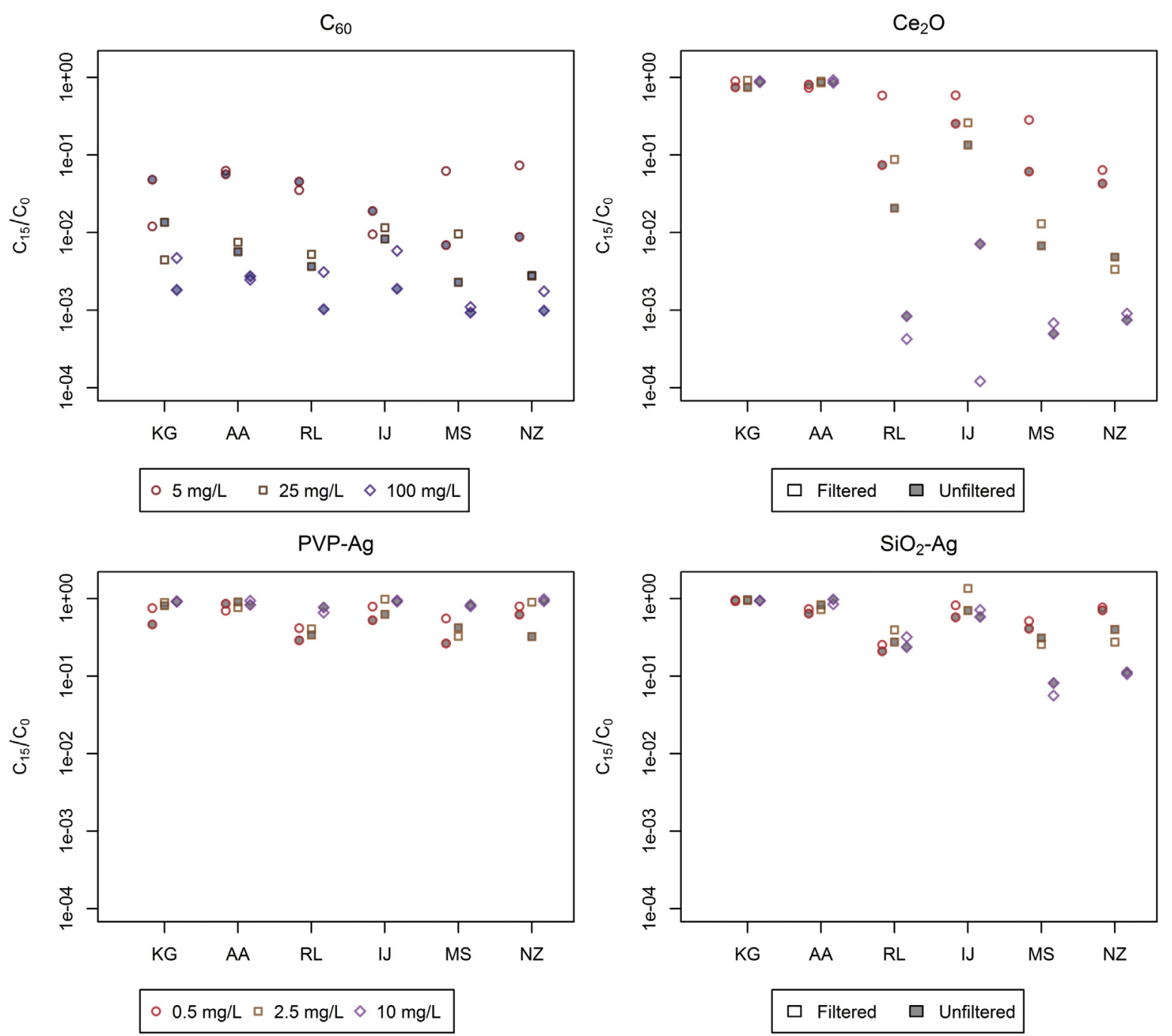

Fig. 2 - Non-settling fractions $\left(\mathrm{C}_{15} / \mathrm{C}_{0}\right)$ for $\mathrm{C}_{60}, \mathrm{CeO}_{2}, \mathrm{PVP}-\mathrm{Ag}$ and $\mathrm{SiO}_{2}-\mathrm{Ag}$ ENMs in 6 different water types with (unfiltered) and without (filtered) natural colloids (NCs) present for 3 different initial ENM concentrations. Water types: Karregat (KG), Brabantse Aa (AA), Rhine (RL), IJsselmeer (IJ), Maassluis (MS) and North Sea (NZ).

the unfiltered systems using values for $k_{\text {hom.crit }}$ obtained from fitting Eq. (5) to sedimentation data for the filtered systems, with $C_{0, N C}=0$. The fitting procedures may use all measured sedimentation data or may use $C_{0}$ and a single time point $C(t)$, for instance after $15 \mathrm{~d}$ only. The latter approach is better if the differences between sedimentation in filtered vs. unfiltered water are too small for the early time points.

\section{Results and discussion}

\subsection{Natural colloids and water types}

In general, NCs increased overall sedimentation of ENMs $\left(\mathrm{mg} \mathrm{L}^{-1}\right)$. The obtained ENM sedimentation rates $\left(\mathrm{m} \mathrm{d}^{-1}\right)$ were not significantly affected by the presence of NCs in the surface waters, nor by the different water types (paired t-test, $p>0.05$, Fig. 1). For the non-settling fraction after 15 days $\left(C_{15} / C_{0}\right)$, a significant decrease was observed in the presence of NCs
( $p<0.01$, Fig. 2) which implies that the settling fraction increased in presence of NCs. In combination, identical sedimentation rates but higher settling fractions upon presence of NCs, explain that NCs increased overall sedimentation. Significant differences between the $C_{15} / C_{0}$ were also observed between most water types, except in the subsets RL, MS, NZ, and AA, KG, IJ (Fig. 2). This suggests a communality in the characteristics of the water types in these sets. The KG, AA and to lesser extend IJ water show significantly higher nonsettling fractions in the water phase after 15 days compared to RL, MS and NZ. The first mentioned group also possesses the more favorable conditions for stability against aggregation, such as higher DOC, lower EC, more extreme $\mathrm{pH}$ and lower NC mass (Hotze et al., 2010; Keller et al., 2010; Ottofuelling et al., 2011). In addition to ENM sedimentation being affected by the presence of NCs, the sedimentation of NCs may also be affected due to heteroaggregation with ENMs. However, using $\mathrm{Al}$ as a proxy for NCs, we observed no significant effect of presence of ENMs on NC settling (Figure A3). 


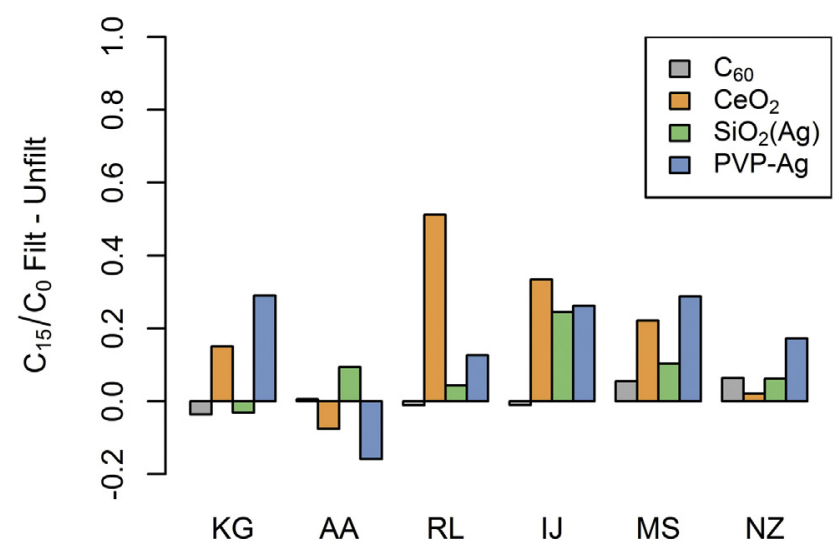

Fig. 3 - Fraction of ENM removed from the water phase due to the presence of NCs. Calculated by subtraction of $C_{15} / C_{0}$ for unfiltered water from $\mathrm{C}_{15} / \mathrm{C}_{0}$ of filtered water, for $0.5 \mathrm{mg} \mathrm{L}^{-1}$ (metal ENM) and $5 \mathrm{mg} \mathrm{L}^{-1}\left(\mathrm{C}_{60}\right)$ initial ENM concentration. Water types: Karregat (KG), Brabantse Aa (AA), Rhine (RL), IJsselmeer (IJ), Maassluis (MS) and North Sea (NZ).

To better isolate the effect that NCs may have on the sedimentation of ENMs from the water phase, we subtracted the $C_{15} / C_{0}$ in unfiltered water from that in filtered river water. This shows that NCs generally increase sedimentation of ENMs (Fig. 3) for the most environmentally relevant initial particle concentration ( 0.5 or $5 \mathrm{mg} \mathrm{L}^{-1} \mathrm{ENM}$ ). The fraction removed due to presence of NCs varies per water type and particle type. In AA water the difference is negative for both $\mathrm{CeO}_{2}$ and PVP-Ag ENMs suggesting a decrease in sedimentation in presence of NCs. This is not in line with the total amount of NCs present in AA water, which has the highest available surface area for interaction with ENMs compared to the other water types (Fig. 4, Figure A4). This suggests that the NCs present in AA water do not directly affect the sedimentation within 15 days. This could be due to the size of the NCs

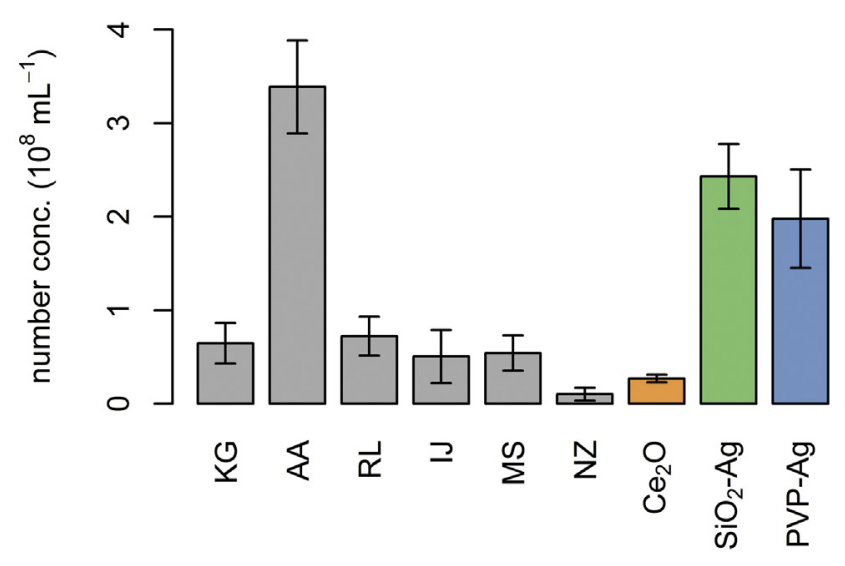

Fig. 4 - Number concentration of NCs and ENMs. NCs in original water and of $0.5 \mathrm{mg} \mathrm{L}^{-1}$ (metal ENM) and $5 \mathrm{mg} \mathrm{L}^{-1}$ $\left(\mathrm{C}_{60}\right)$ ENMs in deionized water as measured by nanoparticle tracking analysis. Water types: Karregat (KG), Brabantse Aa (AA), Rhine (RL), IJsselmeer (IJ), Maassluis (MS) and North Sea (NZ). in AA water, which were measured to be smaller than NCs in the other water types. In the other waters, the larger NCs settle much faster (Figure A3). The low fraction removed for AA water may also relate to the high DOC content of the water. DOC may indicate the presence of lower density NCs, which might not settle within 15 days. Furthermore, DOC (as a proxy for natural organic matter) is known to reduce the attachment efficiency of ENMs resulting in a decrease in aggregation and sedimentation (Li and Chen, 2012; Quik et al., 2010).

\subsection{Sedimentation and stability of ENMs}

The different ENMs showed significant differences in apparent sedimentation rate and $C_{15} / C_{0}$ (paired t-test, $p<0.01$; Fig. 1). The sedimentation rates ranged from $0.0048 \mathrm{~m} \mathrm{~d}^{-1}$ for PVP-Ag to $0.12 \mathrm{~m} \mathrm{~d}^{-1}$ for $\mathrm{C}_{60}$. The apparent non-settling fractions (given as $C_{15} / C_{0} \times 100 \%$ ) after $15 \mathrm{~d}$ varied from $0.01 \%$ to $92 \%$ for the metal based ENMs. Only for $C_{60}$ particles consistently low values of $\mathrm{C}_{15} / \mathrm{C}_{0}$ were observed in all waters; from 1 to $7 \%$. A full overview of all the sedimentation rates and $\mathrm{C}_{15} / \mathrm{C}_{0}$ can be found in the Supporting Information (Table A5). In addition to differences in chemical composition, these ENMs differed in particle coating, size and initial particle number concentrations. The observed number concentrations (Fig. 4) are discussed here because it is important for relative contributions of homo and heteroaggregation, discussed in the next section. The differences in particle size cause differences in particle number concentration for the same $0.5 \mathrm{mg} \mathrm{L}^{-1}$ mass concentration (Fig. 4). The $0.5 \mathrm{mg} \mathrm{L}^{-1} \mathrm{PVP}-\mathrm{Ag}$ and $\mathrm{SiO}_{2}-\mathrm{Ag}$ have similar particle number concentrations. $\mathrm{CeO}_{2}$ however, shows significantly lower particle number concentrations. The $5 \mathrm{mg} \mathrm{L}^{-1} \mathrm{C}_{60}$ particle number concentration (not shown) is even lower, but this is probably not representative due to limitations of the NTA measurement method with regard to large $C_{60}$ aggregates $(>1 \mu \mathrm{m})$. Because (a) the initial ENM concentration appears to affect the sedimentation rate and $\mathrm{C}_{15} / \mathrm{C}_{0}$ of the ENMs (Figs. 2 and 3), and (b) the lower concentrations have a higher environmental relevance, the discussion below will focus on the data obtained at the lowest initial ENM concentrations (Table 2).

Generally, sedimentation rates from other studies span a higher range compared to the range observed in our experiments with 6 different water types in the presence of NCs (Fig. 5). Only the sedimentation rates reported by Keller et al. (2010) span down to similarly low values. There are too many differences in the set-up of these studies to unambiguously explain all differences in observed sedimentation rates. However, generally these earlier studies used higher initial ENM concentrations, which may explain the higher sedimentation rates for these ENMs. Remarkably, the highest sedimentation rates are observed for multi walled carbon nanotubes (Kennedy et al., 2008), regardless of the presence of DOC in the water. This agrees to the much higher sedimentation rates observed for $\mathrm{C}_{60}$ in the present study. Furthermore the study of Battin et al. (2009) showed relatively high sedimentation rates: between 0.10 and $0.28 \mathrm{~m} \mathrm{~d}^{-1}$ using stream microcosms, with and without a biofilm present, as opposed to quiescent settling in the current study. The adsorption of the ENM to the biofilm may have caused these higher sedimentation or removal rates. In our previous studies 


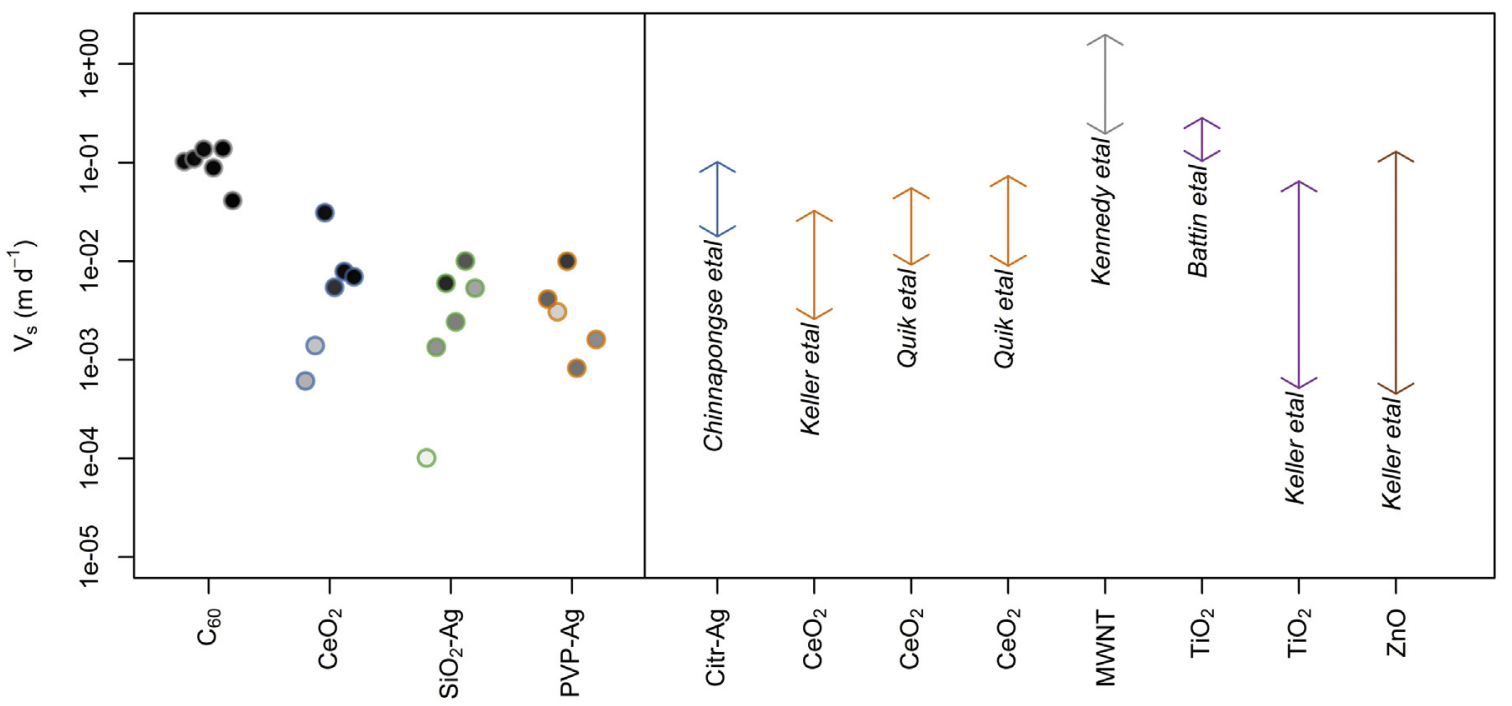

Fig. 5 - Comparison of sedimentation rates (points, this study) to ranges recalculated from literature data (arrows with citation (Battin et al., 2009; Chinnapongse et al., 2011; Keller et al., 2010; Kennedy et al., 2008; Quik et al., 2010 , Quik et al. 2012)).

sedimentation of the same $\mathrm{CeO}_{2}$ ENM as in the present study were tested in algae medium with and without DOC (Quik et al., 2010) and in two natural water samples from the Rhine and Meuse rivers (Quik et al., 2012). The sedimentation rates for $1 \mathrm{mg} \mathrm{L}^{-1} \mathrm{CeO}_{2}$ suspensions in natural water were similar to the rates observed in the present study.

Given the importance of the particle number concentration on aggregation, the contribution of heteroaggregation can only be significant when there are more NC than ENM particles present in suspension. This idea has been postulated (Praetorius et al., 2012; Quik et al., 2011) as a basis for exposure modeling where heteroaggregation is assumed to be the dominant process due to the abundance of NCs being much higher than that of ENMs, given their current and anticipated levels of ENM emission (Gottschalk et al., 2011). For exposure modeling this simplifies Eq. (2) to only the heteroaggregation term. However, we observed the particle number concentration of both of our Ag nanoparticle types to be higher than the NC number concentrations present in the different water types (Fig. 4). Only for $\mathrm{CeO}_{2}$ similar or higher NC number concentrations than ENM number concentrations are observed. Nevertheless, for both $\mathrm{Ag}$ and $\mathrm{CeO}_{2}$ ENMs a higher sedimentation is observed in most water types when NCs are present (Fig. 3). This shows that even at these rather high ENM concentrations, NCs affected sedimentation. However, homoaggregation cannot be excluded as shown by the removal of ENMs in filtered water. Note that, unlike Eqs. 2 and 5 , the empirical model used to estimate apparent sedimentation rates (Eq. (1)) does not explicitly account for all the processes affecting sedimentation, such as homo- and heteroaggregation.

\subsection{Dissolution}

It has been reported that $\mathrm{Ag}$ dissolution is affected by $\mathrm{Ag}$ nanoparticle coating as well as by $\mathrm{pH}$, oxygen content and ionic composition of the water (Ho et al., 2010; Levard et al., 2012; Li et al., 2012). $\mathrm{CeO}_{2}$ is not expected to show any significant dissolution (Quik et al., 2011). In general, dissolution was very limited, with values $<1.5 \%$ for $A A, R L$, IJ and MS and similar for both PVP and $\mathrm{SiO}_{2}$ coated Ag nanoparticles. Higher dissolution was measured in the acid pond water (KG), i.e. between 0.7 and $4 \%$ with a slightly higher dissolution of $\mathrm{SiO}_{2}-\mathrm{Ag}$ than PVP-Ag in these acidic conditions (Fig. 6 and A5). Additionally, KG water is the only water type with a detectable fraction dissolved Ce: $<0.4 \%$. The highest percentage of dissolved Ag (7-12\%), is measured in seawater (NZ).

The measured dissolved fraction of $\mathrm{Ag}$ and Ce after 15 days (Figure A5) was in most cases lower than at the start of the experiment (Fig. 6). This suggests that the stable species of Ag is not a dissolved ion complex, but that precipitation occurs,

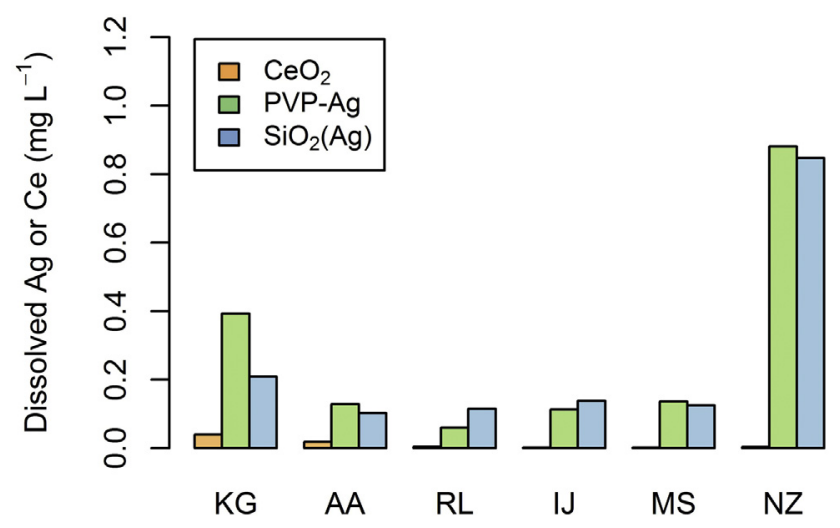

Fig. 6 - Dissolution of $\mathrm{CeO}_{2}, \mathrm{SiO}_{2}-\mathrm{Ag}$ and PVP-Ag ENMs. Dissolved metal ions, Ce and $\mathrm{Ag}$, in $10 \mathrm{mg} \mathrm{L}^{-1} \mathrm{ENM}$ suspensions in six different water types. Water types: Karregat (KG), Brabantse Aa (AA), Rhine (RL), IJsselmeer (I)), Maassluis (MS) and North Sea (NZ). 
most likely of $\mathrm{AgCl}(\mathrm{s})$. Equilibrium speciation calculations suggest that in all water types except seawater, AgCl makes up more than $95 \%$ of the silver species present. For seawater, CHEAQS showed that $98.6 \%$ of Ag present should be in the form of $\mathrm{AgCl}_{4}^{3-}$, which explains the higher dissolution in seawater consistent with literature, which indicated only minor effects of sulfide in seawater (Levard et al., 2012). The diameter of the PVP-Ag particles was significantly lower after 10 days compared to day 1 (Figure A6). This supports the idea that there is continued dissolution causing the shrinking of the Ag NPs in time. It is likely that the increase in the fraction dissolved $\mathrm{Ag}$ is not seen in the filtrate due to the formation of other Ag-containing solids after aging, which do not pass the $3 \mathrm{kDa}$ filter. These observations illustrate the importance of addressing aging and alteration of ENMs under environmental conditions (Nowack et al., 2012).

These results imply that for $\mathrm{CeO}_{2}$ we can neglect $k_{\text {dis }}$ in Eq. (1) compared to the sedimentation term $\left(V_{S} / h\right)$, i.e. we may consider coagulation-sedimentation as the dominating removal process in fresh and brackish water types. This is not always the case for Ag ENMs but the dissolution data do not allow the estimation of $k_{\text {dis }}$. Dissolved Ag ENMs may however have contributed to the apparent non-settling fractions. Consequently, it can be speculated that for $\mathrm{Ag}$ ENMs the $\mathrm{C}_{\mathrm{ns}}$ in Eq. (1) can be up to $12 \%$ lower in seawater. Further measurements aimed at measuring the dissolution kinetics are needed to estimate the dissolution rates under a range of different environmentally relevant conditions. Note that the fact that $k_{\text {dis }}$ for Ag is indeterminate, does not imply that sedimentation rate estimates are inaccurate, as was explained in the materials and methods section.

\subsection{Heteroaggregation rates}

The largest range of $k_{\text {het, crit }}$ values is observed for $\mathrm{C}_{60}$ ENMs, followed by $\mathrm{CeO}_{2}, \mathrm{PVP}-\mathrm{Ag}$ and $\mathrm{SiO}_{2}-\mathrm{Ag}$ ENMs. For all ENMs, the NCs in seawater (NZ) have the highest $k_{\text {het, crit values, }}$ which is explained from the high ionic strength of seawater (Table 2). This agrees to a study by Keller et al. (2010) who reported homoaggregation rates for $\mathrm{CeO}_{2}, \mathrm{TiO}_{2}$ and $\mathrm{ZnO}$ ENMs being the highest in seawater. Also in brackish water (MS) relatively high $k_{\text {het, crit }}$ values were observed. Only for $\mathrm{CeO}_{2}$ in Rhine water (RL) a slightly higher $k_{\text {het, crit }}$ was measured compared to NZ water showing the dominant effect of the NCs in Rhine water on $\mathrm{CeO}_{2}$ ENMs, as previously reported (Quik

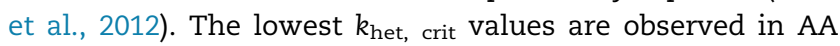
and IJ water, indicating a stabilizing effect of the higher DOC concentrations in these waters (Table 2). This is in line with a study by Huynh et al. (2012) that showed the total inhibition of heteroaggregation between multi walled carbon nanotubes and hematite nanoparticles upon addition of $0.5 \mathrm{mg} \mathrm{L}^{-1}$ humic acid. Heteroaggregation data for $\mathrm{CeO}_{2}$ and PVP-Ag ENMs could not be obtained for water with high DOC concentrations (AA water, Table 2). This is likely due to the fact that filtration also removed some of the natural organic matter leading to increased aggregation compared to the unfiltered sample. Also KG shows relatively low $k_{\text {het, crit values. This is explained }}$ from the stabilization of ENMs due to low ionic strength and low $\mathrm{pH}$, which therefore showed low sedimentation of ENMs in either filtered or unfiltered systems (Fig. 2). In general these results show that water types that generally stabilized ENMs also resulted in lower $k_{\text {het, }}$ crit.

One disclaimer should be mentioned with respect to the use of the data from this study. The reported values are conditional and therefore useful only if applied to waters with similar characteristics. However, note that the use of conditional constants is common in reaction - and equilibrium kinetics, for instance in metal speciation modeling (Radovanovic and Koelmans, 1998). The parameters in Table 2 thus are primarily relevant for fate model implementations for the studied waters. Parameters for other systems, however, may be derived following the methodology proposed in the present work.

\section{Conclusions}

This study provided sedimentation rates, non-settling fractions and heteroaggregation rates for several representative ENMs and a wide range of natural water types. Heteroaggregation with NCs has been shown to play a key role in the sedimentation of ENMs. Furthermore, dissolution has been shown to be relevant for specific combinations of ENM and water types. We conclude that these data as well as the approach to derive them will advance the development of fate and exposure models for ENMs. This study addressed quiescent settling conditions. Further research is needed to address the effect that turbulent conditions may have on heteroaggregation and sedimentation of ENMs.

\section{Acknowledgments}

We thank Ruud Jeths, Gerrie Pieper, Leo van Hal, Erik Steenbergen and Mieke Verheij for their assistance and cooperation regarding sampling of the different water types. This work was funded by the European Union Sixth Framework Program NanoInteract NMP4-CT-2006-033231, the RIVM strategic research program SOR-S340030, and by NanoNextNL, a micro and nanotechnology consortium of the Government of the Netherlands and 130 partners.

\section{Appendix A. Supplementary data}

Supplementary data related to this article can be found at http://dx.doi.org/10.1016/j.watres.2013.09.036.

\section{R E F E R E N C E S}

Afrooz, A.R.M.N., Khan, I.A., Hussain, S.M., Saleh, N.B., 2013. Mechanistic heteroaggregation of gold nanoparticles in a wide range of solution chemistry. Environ. Sci. Technol. 47 (4), 1853-1860.

Arvidsson, R., Molander, S., Sandén, B.A., Hassellov, M., 2011. Challenges in exposure modeling of nanoparticles in aquatic environments. Hum. Ecol. Risk Assess. 17 (1), 245-262.

Batley, G.E., Kirby, J.K., McLaughlin, M.J., 2013. Fate and risks of nanomaterials in aquatic and terrestrial environments. Acc. Chem. Res. 46 (3), 854-862. 
Battin, T.J., Kammer, F.v.d., Weilhartner, A., Ottofuelling, S., Hofmann, T., 2009. Nanostructured $\mathrm{TiO}_{2}$ : transport behavior and effects on aquatic microbial communities under environmental conditions. Environ. Sci. Technol. 43 (21), 8098-8104.

Boyd, C.E., 1995. Bottom Soils, Sediment, and Pond Aquaculture. Chapman \& Hall, New York.

Chen, K.L., Elimelech, M., 2008. Interaction of fullerene (C60) nanoparticles with humic acid and alginate coated silica surfaces: measurements, mechanisms, and environmental implications. Environ. Sci. Technol. 42 (20), 7607-7614.

Chinnapongse, S.L., MacCuspie, R.I., Hackley, V.A., 2011. Persistence of singly dispersed silver nanoparticles in natural freshwaters, synthetic seawater, and simulated estuarine waters. Sci. Total Environ. 409 (12), 2443-2450.

Cornelis, G., Kirby, J.K., Beak, D., Chittleborough, D., McLaughlin, M.J., 2010. A method for determination of retention of silver and cerium oxide manufactured nanoparticles in soils. Environ. Chem. 7 (3), 298-308.

EU (Ed.), 2008. European Union System for the Evaluation of Substances (EUSES). Version 2.1. Institute for Health and Consumer Protection, E.C.B.

Farley, K.J., Morel, F.M.M., 1986. Role of coagulation in the kinetics of sedimentation. Environ. Sci. Technol. 20 (2), 187-195.

Filella, M., 2007. In: Wilkinson, K.J., Lead, J.R. (Eds.),

Environmental Colloids and Particles: Behaviour, Separation, and Characterisation. Wiley.

Friedlander, S.K., 2000. Smoke, Dust, and Haze: Fundamentals of Aerosol Behavior. Oxford University Press, New York.

Gottschalk, F., Ort, C., Scholz, R.W., Nowack, B., 2011. Engineered nanomaterials in rivers - exposure scenarios for Switzerland at high spatial and temporal resolution. Environ. Pollut. 159 (12), 3439-3445.

Gottschalk, F., Sonderer, T., Scholz, R.W., Nowack, B., 2010. Possibilities and limitations of modeling environmental exposure to engineered nanomaterials by probabilistic material flow analysis. Environ. Toxicol. Chem. 29 (5), 1036-1048.

Hendren, C.O., Mesnard, X., Droge, J., Wiesner, M.R., 2011. Estimating production data for five engineered nanomaterials as a basis for exposure assessment. Environ. Sci. Technol. 45 (7), 2562-2569.

Ho, C.M., Yau, S.K.W., Lok, C.N., So, M.H., Che, C.M., 2010. Oxidative dissolution of silver nanoparticles by biologically relevant oxidants: a kinetic and mechanistic study. Chem. An Asian J. 5 (2), 285-293.

Hotze, E.M., Phenrat, T., Lowry, G.V., 2010. Nanoparticle aggregation: challenges to understanding transport and reactivity in the environment. J. Environ. Qual. 39 (6), 1909-1924.

Huynh, K.A., McCaffery, J.M., Chen, K.L., 2012. Heteroaggregation of multiwalled carbon nanotubes and hematite nanoparticles: rates and mechanisms. Environ. Sci. Technol. 46 (11), 5912-5920.

Hyung, H., Fortner, J.D., Hughes, J.B., Kim, J.H., 2007. Natural organic matter stabilizes carbon nanotubes in the aqueous phase. Environ. Sci. Technol. 41 (1), 179-184.

Keller, A.A., Wang, H., Zhou, D., Lenihan, H.S., Cherr, G., Cardinale, B.J., Miller, R., Ji, Z., 2010. Stability and aggregation of metal oxide nanoparticles in natural aqueous matrices. Environ. Sci. Technol. 44 (6), 1962-1967.

Kennedy, A.J., Hull, M.S., Steevens, J.A., Dontsova, K.M., Chappell, M.A., Gunter, J.C., Weiss, C.A., 2008. Factors influencing the partitioning and toxicity of nanotubes in the aquatic environment. Environ. Toxicol. Chem. 27 (9), 1932-1941.

Klaine, S.J., Koelmans, A.A., Horne, N., Handy, R.D., Kapustka, L., Nowack, B., von der Kammer, F., 2012. Paradigms to assess the environmental impact of manufactured nanomaterials. Environ. Toxicol. Chem. 31, 3-14.
Levard, C., Hotze, E.M., Lowry, G.V., Brown, G.E., 2012. Environmental transformations of silver nanoparticles: impact on stability and toxicity. Environ. Sci. Technol..

Li, K., Chen, Y., 2012. Effect of natural organic matter on the aggregation kinetics of $\mathrm{CeO}_{2}$ nanoparticles in $\mathrm{KCl}$ and $\mathrm{CaCl}_{2}$ solutions: measurements and modeling. J. Hazard. Mater. 209-210, 264-270.

Li, X., Lenhart, J.J., Walker, H.W., 2012. Aggregation kinetics and dissolution of coated silver nanoparticles. Langmuir 28 (2), 1095-1104.

Lin, D., Tian, X., Wu, F., Xing, B., 2010. Fate and transport of engineered nanomaterials in the environment. J. Environ. Qual. 39 (6), 1896-1908.

Morris, J., Willis, J., De Martinis, D., Hansen, B., Laursen, H., Sintes, J.R., Kearns, P., Gonzalez, M., 2011. Science policy considerations for responsible nanotechnology decisions. Nat Nano 6 (2), 73-77.

Newman, K.A., Morel, F.M.M., Stolzenbach, K.D., 1990. Settling and coagulation characteristics of fluorescent particles determined by flow cytometry and fluorometry. Environ. Sci. Technol. 24 (4), 506-513.

Nowack, B., Bucheli, T.D., 2007. Occurrence, behavior and effects of nanoparticles in the environment. Environ. Pollut. 150 (1), $5-22$.

Nowack, B., Ranville, J.F., Diamond, S., Gallego-Urrea, J.A., Metcalfe, C., Rose, J., Horne, N., Koelmans, A.A., Klaine, S.J., 2012. Potential scenarios for nanomaterial release and subsequent alteration in the environment. Environ. Toxicol. Chem. 31 (1), 50-59.

Ottofuelling, S., Von Der Kammer, F., Hofmann, T., 2011. Commercial titanium dioxide nanoparticles in both natural and synthetic water: comprehensive multidimensional testing and prediction of aggregation behavior. Environ. Sci. Technol. 45 (23), 10045-10052.

Petersen, E.J., Zhang, L., Mattison, N.T., O'Carroll, D.M., Whelton, A.J., Uddin, N., Nguyen, T., Huang, Q., Henry, T.B., Holbrook, R.D., Chen, K.L., 2011. Potential release pathways, environmental fate, and ecological risks of carbon nanotubes. Environ. Sci. Technol. 45 (23), 9837-9856.

Petosa, A.R., Jaisi, D.P., Quevedo, I.R., Elimelech, M., Tufenkji, N., 2010. Aggregation and deposition of engineered nanomaterials in aquatic environments: role of physicochemical interactions. Environ. Sci. Technol. 44 (17), 6532-6549.

Praetorius, A., Scheringer, M., Hungerbühler, K., 2012. Development of environmental fate models for engineered nanoparticles - a case study of $\mathrm{TiO}_{2}$ nanoparticles in the Rhine River. Environ. Sci. Technol. 46 (12), 6705-6713.

Quik, J.T.K., Lynch, I., Van Hoecke, K., Miermans, C.J.H., De Schamphelaere, K.A.C., Janssen, C.R., Dawson, K.A., Cohen Stuart, M.A., Van De Meent, D., 2010. Effect of natural organic matter on cerium dioxide nanoparticles settling in model fresh water. Chemosphere 81 (6), 711-715.

Quik, J.T.K., Stuart, M.C., Wouterse, M., Peijnenburg, W., Hendriks, A.J., van de Meent, D., 2012. Natural colloids are the dominant factor in the sedimentation of nanoparticles. Environ. Toxicol. Chem. 31 (5), 1019-1022.

Quik, J.T.K., Vonk, J.A., Hansen, S.F., Baun, A., Van De Meent, D., 2011. How to assess exposure of aquatic organisms to manufactured nanoparticles? Environ. Int. 37, 1068-1077.

R Development Core Team, 2012. R: a Language and Environment for Statistical Computing. URL http://www.R-project.org/ (Vienna, Austria).

Radovanovic, H., Koelmans, A.A., 1998. Prediction of in situ trace metal distribution coefficients for suspended solids in natural waters. Environ. Sci. Technol. 32, 753-759. 
Van Hoecke, K., De Schamphelaere, K.A.C., Van der Meeren, P., Smagghe, G., Janssen, C.R., 2011. Aggregation and ecotoxicity of $\mathrm{CeO}_{2}$ nanoparticles in synthetic and natural waters with variable $\mathrm{pH}$, organic matter concentration and ionic strength. Environ. Pollut. 159 (4), 970-976.

Van Hoecke, K., Quik, J.T.K., Mankiewicz-Boczek, J., De

Schamphelaere, K.A.C., Elsaesser, A., Van der Meeren, P., Barnes, C., McKerr, G., Howard, C.V., Van De Meent, D., Rydzyninski, K., Dawson, K.A., Salvati, A., Lesniak, A., Lynch, I., Silversmit, G., De Samber, B., Vincze, L., Janssen, C.R., 2009. Fate and effects of $\mathrm{CeO}_{2}$ nanoparticles in aquatic ecotoxicity tests. Environ. Sci. Technol. 43 (12), 4537-4546.

Verweij, W., 2011. CHEAQS, Computer Program for Calculating CHemical Equilibria in AQuatic Systems.

Westerhoff, P., Nowack, B., 2013. Searching for global descriptors of engineered nanomaterial fate and transport in the environment. Acc. Chem. Res. 46 (3), 844-853.

Wiesner, M.R., Lowry, G.V., Alvarez, P., Dionysiou, D., Biswas, P., 2006. Assessing the risks of manufactured nanomaterials. Environ. Sci. Technol. 40 (14), 4336-4345.

Please cite this article in press as: Quik, J.T.K., et al., Heteroaggregation and sedimentation rates for nanomaterials in natural waters, Water Research (2013), http://dx.doi.org/10.1016/j.watres.2013.09.036 